\title{
Gracilis free muscle transfer for restoration of function after complete brachial plexus avulsion
}

\author{
Kimberly A. Barrie, M.D., Scott P. Steinmann, M.D., Alexander Y. Shin, M.D., \\ Robert J. SPINNER, M.D., AND Allen T. Bishop, M.D. \\ Triangle Orthopaedic Associates, Durham, North Carolina; and Department of Orthopaedic Surgery \\ (Division of Hand Surgery), and Neurologic Surgery, and Brachial Plexus Clinic, Mayo Clinic, \\ Rochester, Minnesota
}

\begin{abstract}
Object. The authors report the functional outcomes after functioning free muscle transfer (FFMT) for restoration of the upper-extremity movement after brachial plexus injury (BPI).

Methods. The authors conducted a retrospective review of 36 gracilis FFMT procedures performed in 27 patients with BPI between 1990 and 2000. Eighteen patients underwent a single gracilis FFMT procedure for restoration of either elbow flexion (17 cases) or finger flexion (one case). Nine patients underwent a double free muscle transfer for simultaneous restoration of elbow flexion and wrist extension (first muscle) and finger flexion (second muscle), combined with direct triceps neurotization. The results obtained in 29 cases of FFMT in which the follow-up period was 1 year are reported.

Neurotization of the donor muscle was performed using the musculocutaneous nerve (one case), spinal accessory nerve (12 cases), or multiple intercostal motor nerves (16 cases). Two second-stage muscle flaps failed secondary to vascular insufficiency. Mean electromyography-measured reinnervation time was 5 months. At a minimum follow-up period of 1 year, five muscles achieved less than or equal to Grade M2, eight Grade M3, four Grade M4, and 12 Grade M5. Transfer for combined elbow flexion and wrist extension compared with elbow flexion alone lowered the overall results for elbow flexion strength. Seventy-nine percent of the FFMTs for elbow flexion alone (single transfer) and $63 \%$ of similarly innervated muscles transferred for combined motion achieved at least Grade M4 elbow flexion strength.

Conclusions. Functioning free muscle transfer is a viable reconstructive option for restoration of upper-extremity function in the setting of severe BPI. It is possible to achieve good to excellent outcomes in terms of muscle grades with the simultaneous reconstruction of two functions by one FFMT, making restoration of basic hand function possible. More reliable results are obtained when a single FFMT is performed for a single function.
\end{abstract}

\section{KEY WORDS • brachial plexus injury • muscle transfer • graft $\bullet$ gracilis muscle}

Traumatic brachial plexopathies are a diverse and complex group of injuries that result in functional upper-extremity deficits ranging from weakness to complete paralysis. Advances in microsurgical techniques have led to innovations in surgical reconstruction of the upper extremity after BPI. Biceps and shoulder musculature reinnervation involving both nerve grafting and transfer techniques has resulted in reliable restoration of elbow flexion and shoulder abduction when the procedure is undertaken within 6 to 9 months of injury. 2,5,6,13,14,17-22

In many instances, however, delay in treatment or complete avulsion of the brachial plexus limits the reconstruction options. The number of available extraplexal donor nerves is limited, and timing of reconstructive procedures becomes critical. Despite favorable results reported for

Abbreviations used in this paper: BMRC = British Medical Research Council; BPI = brachial plexus injury; EMG = electromyography; FFMT = function free muscle transfer; $\mathrm{ROM}=$ range of motion; SSEP = somatosensory evoked potential. early nerve grafting and transfer techniques, attempts at restoring function to long-standing denervated muscle have not been generally successful. ${ }^{6,18,20,21}$ This has resulted in the use of FFMTs in conjunction with extraplexal motor nerves to restore function in the setting of brachial plexus avulsions or when the interval between injury and surgery is greater than 1 year. ${ }^{1,3,7-12,16}$ Free muscle transfer procedures produce reliable elbow flexion when treatment delay prevents direct graft or biceps neurotization, or when previous nerve grafting and/or nerve transfer has yielded unsatisfactory results and proximal muscle strength is insufficient to allow tendon transfers. $1,3,7-13$ They may also prove useful to allow grasp function when intervention occurs soon after injury. Doi, et al., ${ }^{12}$ have described a method involving two FFMTs combined with additional motor and sensory neurotization in patients with four or five nerve root avulsions. In addition to restoration of elbow flexion, this double free muscle transfer provides an opportunity for patients with complete brachial plexus avulsions to regain prehension., , $^{3-12}$

In this study we report the functional outcomes of gra- 
cilis FFMTs for restoration of upper-extremity function after BPI. Both single and double free muscle transfer procedure were performed using extraplexal donor motor nerves.

\section{CLINICAL MATERIAL AND METHODS}

\section{Patient Population}

Our institutional review board approved a retrospective review of all cases involving BPIs in which FFMTs were performed to restore arm function. Between 1990 and 2000 we used gracilis muscle to perform 36 FFMTs in 27 patients with BPIs. We report the results of 29 muscle transfers in 23 patients who attended follow-up evaluation for a minimum of 1 year. There were 20 male and three female patients who ranged in age from 10 to 49 years (mean 25 years) at surgery. The dominant extremity was involved in 14 of the 23 patients. Diagnosis of the injury level was established by clinical evaluation, electrodiagnostic studies, and cervical myelography. Confirmation of the preoperative diagnosis was made by surgical exploration and intraoperative monitoring of SSEPs. In 15 patients complete C5-T1 brachial plexus avulsions were present.

\section{Summary of Procedures}

The mean interval between injury and the first free muscle transfer was 21 months (range 2-143 months). All patients underwent a surgical exploration of the brachial plexus. Fifteen patients underwent a single-target FFMT for restoration of either elbow flexion (17 cases) or finger flexion (one case) (Table 1). Eight patients underwent a double-target free muscle transfer allowing simultaneous restoration of elbow flexion and wrist extension (first muscle) and finger flexion (second muscle), combined with direct triceps neurotization (Table 2). Neurotization of the donor muscle was performed using the musculocutaneous nerve (one case), spinal accessory (11th cranial) nerve (12 cases), or multiple intercostal motor nerves (16 cases). Recovery of motor function was graded using a modification of the BRMC grading system (Table 3).

Reinnervation of the transferred muscle was assessed by clinical examination and confirmed by electrodiagnostic studies 3 to 12 months postoperatively. Eight patients underwent secondary reconstructive procedures including four tendon transfers (one with a wrist fusion), and one case each of the following: wrist disarticulation, shoulder arthrodesis, dorsal wrist tenodesis, intercostal nerve neurotization of the anterior interosseous nerve, gracilis tenolysis with creation of a pulley, and isolated tenolysis. Three patients underwent postoperative reexplorations secondary to arterial thrombosis (one case) and reexploration of the nerve neurotization (two cases).

\section{Operative Techniques}

Gracilis Muscle Harvest. The gracilis muscle was selected as a donor muscle based on its functional capacity to mimic the arm and forearm musculature, microvascular supply, and minimal donor-site morbidity. The gracilis is a superficial muscle that lies on the medial aspect of the thigh. A branch of the obturator nerve that enters the muscle 6 to $12 \mathrm{~cm}$ from its origin provides motor innervation. The dominant arterial supply is provided by a branch from the profunda femoris artery 8 to $12 \mathrm{~cm}$ from the muscular origin and its length is approximately 4 to 6 $\mathrm{cm}$. The muscle is released from the pubic symphysis proximally and from its tendonous insertion at the pes anserinus distally. The gracilis is routinely transferred with a skin paddle for postoperative flap motoring. ${ }^{15}$

Single Gracilis Transfer. In 17 patients the gracilis was used in the FFMT for restoration of elbow flexion. One

TABLE 1

Summary of data obtained in patients undergoing single gracilis muscle transfer*

\begin{tabular}{|c|c|c|c|c|c|c|c|}
\hline $\begin{array}{l}\text { Case } \\
\text { No. }\end{array}$ & $\begin{array}{l}\text { Age (yrs), } \\
\text { Sex }\end{array}$ & $\begin{array}{l}\text { Dominant } \\
\text { Hand }\end{array}$ & Injury Mechanism & Injury & $\begin{array}{l}\text { Duration } \\
\text { From Injury } \\
\text { to Op (mos) }\end{array}$ & Donor Nerve & Donor Vessel \\
\hline 1 & $30, \mathrm{M}$ & no & snowmobile & complete C5-7 avulsion & 17 & SAN & thoracoacromial \\
\hline 2 & $21, \mathrm{M}$ & no & MCA & complete $\mathrm{C} 5-\mathrm{T} 1$ avulsion & 3 & SAN & brachial \\
\hline 3 & $21, \mathrm{~F}$ & no & MVA & complete C5-T1 avulsion & 15 & SAN & thoracoacromial \\
\hline 4 & $49, \mathrm{M}$ & no & pedestrian struck & complete C5-T1 avulsion & 17 & SAN & thoracoacromial \\
\hline 5 & $23, \mathrm{M}$ & yes & MCA & complete $\mathrm{C} 5-\mathrm{T} 1$ avulsion & 71 & ICNs $3 \& 4$ & brachial \\
\hline 6 & $30, \mathrm{M}$ & yes & MCA & complete C5-T1 avulsion & 20 & ICNs $3 \& 4$ & brachial \\
\hline 7 & $28, \mathrm{~F}$ & yes & MVA & incomplete $\mathrm{C} 5-\mathrm{T} 1$ avulsion & 143 & ICNs $3 \& 4$ & brachial \\
\hline 8 & $34, \mathrm{M}$ & yes & industrial & complete C5-T1 avulsion & 63 & ICNs $3 \& 4$ & axillary \\
\hline 9 & $32, \mathrm{M}$ & yes & MCA & complete $\mathrm{C} 6-\mathrm{T} 1$ avulsion & 24 & ICNs $3 \& 4$ & brachial \\
\hline 10 & $16, \mathrm{M}$ & yes & fall & complete $\mathrm{C} 5-\mathrm{T} 1$ avulsion & 2 & ICNs $3 \& 4$ & brachial \\
\hline 11 & $25, \mathrm{M}$ & no & MVA & complete $\mathrm{C} 5-\mathrm{T} 1$ avulsion & 12 & ICNs $3 \& 4$ & axillary \\
\hline \multirow[t]{2}{*}{12} & $26, \mathrm{M}$ & yes & MVA & complete $\mathrm{C} 5-6$ avulsion & & & \\
\hline & & & & incomplete $\mathrm{C}-7$ & 10 & ICNs $3 \& 4$ & brachial \\
\hline 13 & $10, \mathrm{M}$ & no & MVA & incomplete C5-T1 & 65 & ICNs $4 \& 5$ & brachial \\
\hline 14 & $30, \mathrm{M}$ & yes & industrial & $\begin{array}{l}\text { musculocutaneous nerve/ } \\
\text { median nerve }\end{array}$ & 38 & $\begin{array}{l}\text { musculocutaneous } \\
\text { nerve }\end{array}$ & lat pectoral \\
\hline $15 \dagger$ & $24, \mathrm{M}$ & no & MVA & $\begin{array}{l}\text { incomplete C5-6, } \\
\text { complete C7-T1 }\end{array}$ & 38 & ICNs $3 \& 4$ & thoracoacromial \\
\hline
\end{tabular}

* ICN = intercostal nerve; MCA = motorcycle accident; MVA = motor vehicle accident; SAN = spinal accessory nerve.

$\dagger$ This patient underwent transfer for finger flexion. 


\section{Gracilis muscle transfer after BPI}

TABLE 2

Summary of data obtained in patients undergoing double gracilis muscle transfer*

\begin{tabular}{|c|c|c|c|c|c|c|c|}
\hline $\begin{array}{l}\text { Case } \\
\text { No. }\end{array}$ & $\begin{array}{l}\text { Age (yrs), } \\
\text { Sex }\end{array}$ & $\begin{array}{l}\text { Dominant } \\
\text { Hand }\end{array}$ & $\begin{array}{c}\text { Injury } \\
\text { Mechanism }\end{array}$ & Injury & $\begin{array}{c}\text { Duration (mos) } \\
\text { From Injury to } \\
\text { Op (1st/2nd transfer) }\end{array}$ & $\begin{array}{l}\text { Donor Nerve } \\
\text { (1st/2nd transfer) }\end{array}$ & $\begin{array}{c}\text { Donor Vessel } \\
\text { (1st/2nd transfer) }\end{array}$ \\
\hline 1 & $21, \mathrm{M}$ & yes & MCA & complete $\mathrm{C} 5-\mathrm{T} 1$ avulsion & $6 / 8$ & SAN/ICNs $3 \& 4$ & thoracoacromial/brachial \\
\hline 3 & $19, \mathrm{M}$ & yes & MVA & $\begin{array}{l}\text { incomplete C-5, complete } \\
\text { C6-T1 avulsion }\end{array}$ & $4 / 0$ & SAN/- & thoracoacromial/- \\
\hline 4 & $19, \mathrm{M}$ & yes & snowmobile & complete C5-T1 avulsion & $7 / 9$ & SAN/ICNs $3 \& 4$ & thoracoacromial/thoracoacromial \\
\hline 7 & $26, \mathrm{M}$ & yes & snowmobile & complete $\mathrm{C} 5-\mathrm{T} 1$ avulsion & $4 / 6$ & SAN/ICNs $(3,5)$ & thoracoacromial/thoracoacromial \\
\hline 8 & $25, \mathrm{M}$ & no & MCA & complete $\mathrm{C} 5-\mathrm{T} 1$ avulsion & $6 / 9$ & SAN/ICNs $4 \& 5$ & thoracoacromial/thoracoacromial \\
\hline
\end{tabular}

$*_{-}=$Second transfer failed at at the time of surgery caused by no-reflow phenomenon.

patient underwent a muscle transfer for restoration of finger flexion. In 15 patients the follow-up period was 1 year or more. Two intercostal motor nerves were used as donor nerves in 10 cases, the distal portion of the spinal accessory nerve was used as a donor nerve in four cases, and the musculocutaneous nerve was used in one case (Fig. 1). Selection of a donor nerve was based on multiple factors including surgeon's preference and nerve availability.

TABLE 3

Summary of functional recovery as identified by BMRC guides*

\begin{tabular}{|c|c|}
\hline Grade & Definition \\
\hline \multicolumn{2}{|l|}{ motor } \\
\hline M0 & no contraction \\
\hline M1 & EMG reinnervation, no joint motion \\
\hline \multirow[t]{2}{*}{ M2 } & perceptible joint movements \\
\hline & $\begin{array}{l}\text { no elbow flexion against gravity }\left(\mathrm{AROM}<45^{\circ}\right) \\
\text { finger flexion-extension (perceptible finger movements with } \\
\text { wrist flexed) }\end{array}$ \\
\hline \multirow[t]{3}{*}{ M3 } & sufficient power to act against gravity \\
\hline & elbow flexion (AROM 45-90º \\
\hline & $\begin{array}{l}\text { finger flexion-extension }\left(\mathrm{ROM}(\mathrm{TAM}) \geq 30^{\circ} \text { from full }\right. \\
\text { extension or flexion) }\end{array}$ \\
\hline \multirow[t]{3}{*}{ M4 } & muscle acts against some resistance \\
\hline & elbow flexion (AROM $>90^{\circ}$, lifts $2-\mathrm{kg}$ weight $<30$ times) \\
\hline & $\begin{array}{l}\text { finger flexion/extension (ROM }[\text { TAM }] \geq 60^{\circ} \text { from full } \\
\text { extension or flexion) }\end{array}$ \\
\hline \multirow[t]{4}{*}{ M5 } & muscle acts against strong resistance \\
\hline & elbow flexion (AROM $>90^{\circ}$, lifts $2-\mathrm{kg}$ weight $\geq 30$ times) \\
\hline & finger flexion/extension (ROM $[\mathrm{TAM}] \geq 90^{\circ}$ from full \\
\hline & extension or flexion; lifting a 5-kg object w/ 1 hand) \\
\hline \multicolumn{2}{|c|}{ sensory } \\
\hline \multirow{2}{*}{$\begin{array}{l}\text { S0 } \\
\text { S1 }\end{array}$} & no recovery of sensibility in autonomous zone of nerve \\
\hline & $\begin{array}{l}\text { recovery of deep cutaneous pain sensibility } \\
\quad \text { (no. } 20 \text { red on Semmes-Weinstein monofilament test) }\end{array}$ \\
\hline $\mathrm{S} 2$ & $\begin{array}{l}\text { recovery of some superficial cutaneous pain \& tactile sensibility } \\
\text { w/in autonomous area }\end{array}$ \\
\hline $\mathrm{S} 2+$ & $\begin{array}{l}\text { some recovery of } 2-p t \text { discrimination }(>15 \mathrm{~mm}) \\
\text { (no. } 10 \text { yellow on Semmes-Weinstein monofilament test) }\end{array}$ \\
\hline S3 & $\begin{array}{l}\text { recovery of pain \& touch sensibility }(>15 \mathrm{~mm}) \\
\text { disappearance of over response }\end{array}$ \\
\hline $\mathrm{S} 3+$ & $\begin{array}{l}\text { return of sensibility of 2-pt discrimination }(7-15 \mathrm{~mm}) \\
\quad \text { (no. } 6 \text { blue on Semmes-Weinstein monofilament test) }\end{array}$ \\
\hline \multirow[t]{2}{*}{$\mathrm{S} 4$} & complete recovery of 2 pts $(2-6 \mathrm{~mm})$ \\
\hline & (no. 4 green on Semmes-Weinstein monofilament test) \\
\hline
\end{tabular}

* $\mathrm{AROM}=$ active range of motion; $\mathrm{TAM}=$ total active motion .
In cases involving intercostal neurotization, the intercostal motor nerves were exposed via either an inframammary or a parasternal incision. Subperiosteal mobilization of the third and fourth ribs exposed the intercostal muscle and avoided pleura injury. Blunt dissection in the cephalad portion of each intercostal muscle allowed identification of the intercostal motor nerve, which was confirmed using a nerve stimulator. The third and fourth intercoastal nerves were primarily used as donor nerves because of their proximity to the harvested gracilis neurovascular pedicle. The intercostal nerves were dissected distally to the point at which muscle contraction ceased (generally near the costal chondral cartilage junction) and proximally to the anterior axillary line.

When the spinal accessory nerve was used, it was identified on the deep anterior surface of the trapezius muscle and confirmed using a nerve stimulator. The most proximal motor branch to the trapezius was identified and protected to preserve muscle function. The remainder of the motor branch was mobilized for neurotization, sacrificing other trapezial motor branches, as necessary, to facilitate mobilization and nerve transposition beneath the clavicle. Eight brachial arteries, four thoracoacromial trunks, two axillary arteries, and one lateral pectoral artery were used for the arterial anastomosis, and their vena comitantes or the cephalic vein was selected for venous anastomosis.

In patients seen within 3 to 6 months of injury, surgical exploration of the brachial plexus was performed and nerve root avulsion confirmed using intraoperative SSEP monitoring before performing free muscle transfer. In cases of long-standing paralysis, plexus exploration was not undertaken. The gracilis muscle was dissected and the recipient site prepared to receive the transfer before its vascular pedicle was divided. Once freed from the leg, it was brought immediately to the arm and positioned within the recipient site, in most cases for elbow flexion. In such cases, it is desirable to position the gracilis muscle as close to the donor motor nerve as possible to minimize reinnervation time and to avoid the use of an intercalated nerve graft. When the spinal accessory nerve is to be used, this is accomplished by fixing the gracilis proximally by placing it beneath the clavicle and wrapping it around the cephalad and anterior clavicular surface. The gracilis is then sutured into place via multiple clavicle drill holes. 


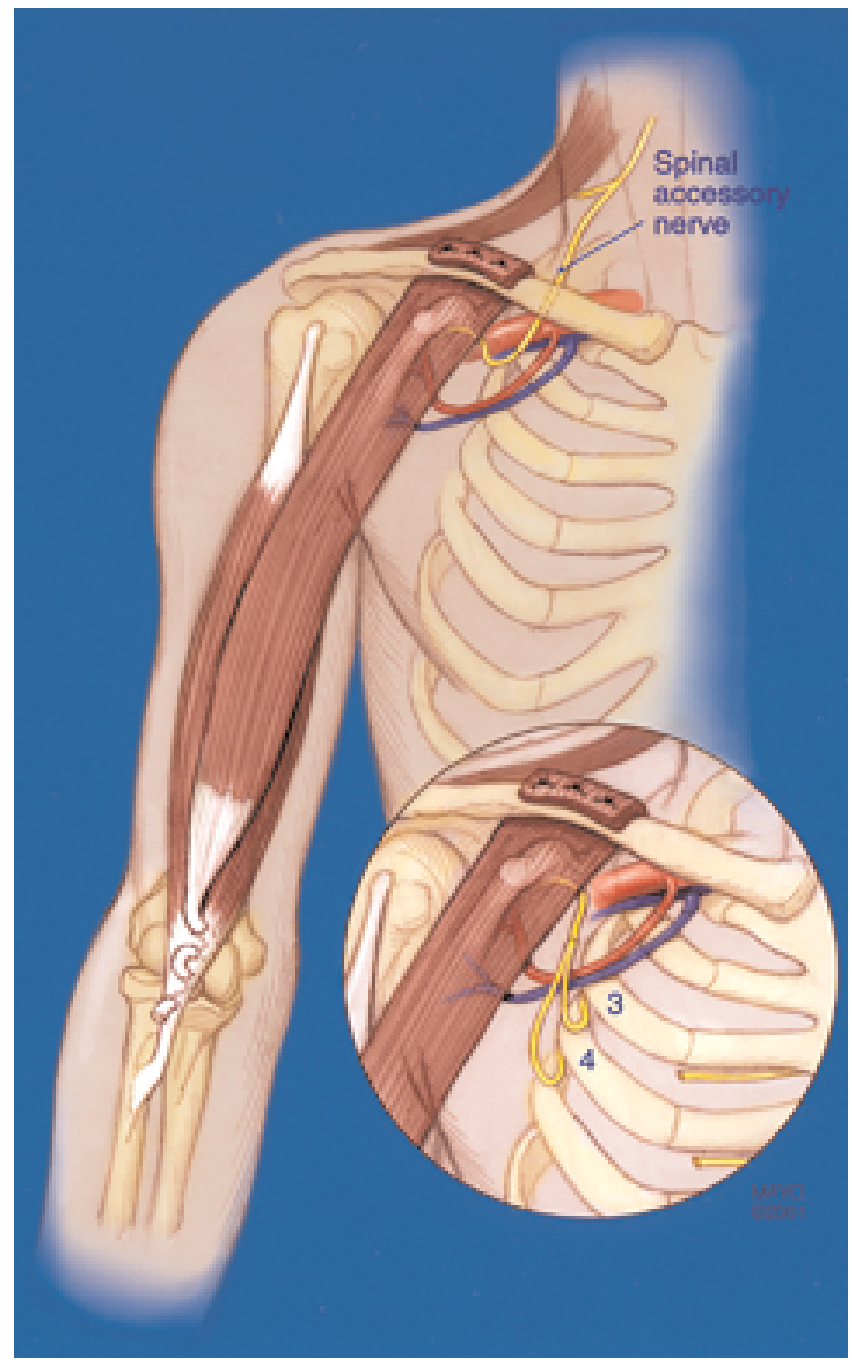

Fig. 1. Illustration of the gracilis FFMT for restoration of elbow flexion. The gracilis muscle is secured proximally to the clavicle and distally to the biceps tendon. Motor innervation is provided by either the spinal accessory nerve or multiple intercostal motor nerves (inset). (Copyright of the Mayo Foundation. Reproduced with permission.)

The spinal accessory nerve is dissected as distally as possible because this generally permits its passage beneath the clavicle in proximity to the base of the gracilis neurovascular pedicle. The muscle is tunneled subcutaneously to a separate antecubital incision. End-to-end or end-to-side arterial repairs are acceptable. When the thoracoacromial trunk is used (the authors' preference for elbow flexion transfers), direct end-to-end arterial repair is most appropriate, followed by venous anastomosis. The distal tendon was secured to the biceps tendon via a pulvertaft weave following completion of the vessel anastomoses and neurorrhaphy (Fig. 1). Tensioning of the transferred muscle was performed with the arm held in $30^{\circ}$ of flexion with the muscle at its normal resting length.

Double Gracilis Transfer. Nine patients underwent a double-target FFMT procedure, originally described by Doi, et al. ${ }^{12}$ Eight patients attended follow-up examination for 1 year or more. The technique for upper-extremity reconstruction after complete brachial plexus avulsion consists of two procedures, each requiring a gracilis muscle transfer. The first stage involves surgical exploration of the brachial plexus with SSEP monitoring. The first gracilis FFMT restores elbow flexion and finger or wrist extension. The gracilis is secured to the clavicle proximally as previously described. The distal tendon is tunneled beneath the mobile wad just proximal to the elbow and sutured to the extensor carpi radialis brevis tendon in the proximal portion of the forearm. Tensioning of the muscle transfer was fashioned to permit elbow flexion with a $30^{\circ}$ flexion contracture and simultaneous passive finger or wrist extension, while allowing full wrist flexion with the elbow flexed. The first gracilis transfer is neurotized to the spinal accessory nerve, and the vascular pedicle is anastomosed to the thoracoacromial trunk (Fig. 2 left).

The second gracilis transfer restores finger flexion. Proximally the gracilis is secured to the second rib via multiple drill holes. Distally a second incision is made in the forearm and the flexor digitorum profundus and flexor pollicis longus tendons are identified and sutured together in a position that creates key pinch and grasp with traction. The distal tendon is tunneled from the arm to the forearm beneath the pronator teres to create a pulley effect. The tendon is then woven into the previously prepared flexor digitorum profundus and flexor pollicis longus tendons by using a Pulvertaft weave. The graft is tensioned to allow the fingers to extend with elbow flexion and to permit the fingers and thumb to close with elbow extension. The second gracilis transfer was neurotized by two intercostal motor nerves, and the vascular pedicle was anastomosed to the thoracodorsal artery and vein (Fig. 2 right).

In addition to the second gracilis transfer, the second stage requires neurotization of two intercostal motor nerves to the motor branch of the triceps brachii muscle (Fig. 2 right). Restoration of elbow extension permits better control of the distal joint function provided by the functioning free muscles crossing the elbow, allowing its active stabilization. In addition, sensory neurotization of the lateral portion of the median nerve with sensory intercostal nerves is performed to restore protective hand sensibility (Fig. 3).

\section{Postoperative Management}

Postoperatively the upper limb is immobilized for 4 weeks with the wrist in neutral position and the proximal and distal interphalangeal joints in extension. Electromyographic evidence of reinnervation of the transferred muscles is obtained within the first 3 to 12 months. Once this is confirmed clinically or electrically, EMG feedback techniques are initiated as is passive ROM.

\section{Outcome Assessment}

Motor Evaluation. Elbow functional outcome was based on ROM and endurance. The functional outcome of finger motion was based on the total active motion of the fingers. Motor recovery for elbow and finger ROM was graded based on a modification of the grading systems of Doi, et al., ${ }^{8}$ and Songcharoen, et al., ${ }^{21}$ (Table 3). 


\section{Gracilis muscle transfer after BPI}
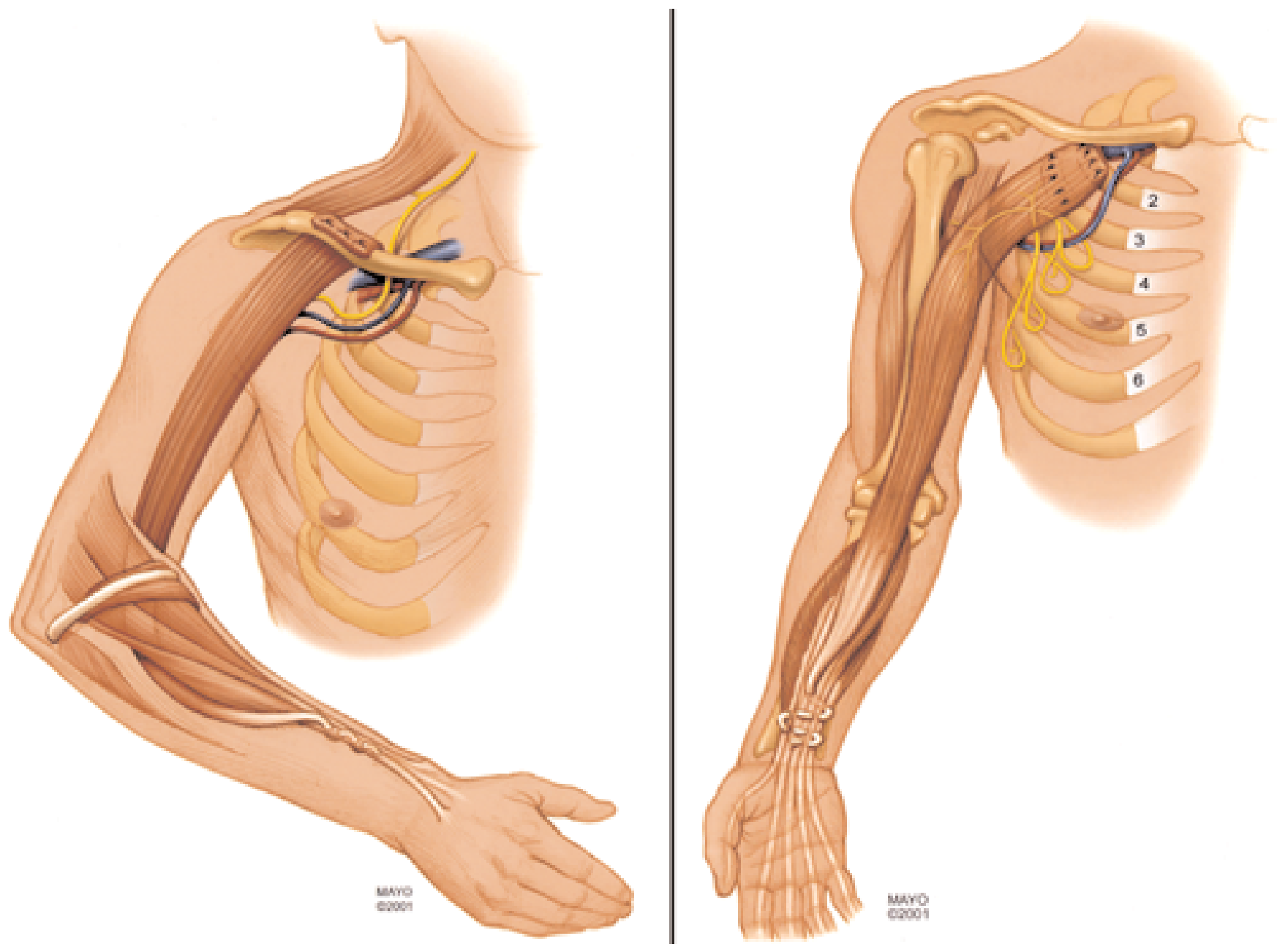

Fig. 2. Doi Stage I and II procedures. Left: Stage I. Double free muscle transfer is used for restoration of elbow flexion and wrist extension. Motor neurotization is provided by the spinal accessory nerve. Right: Stage II. Double free muscle transfer is used for restoration of finger flexion. Motor neurotization is provided by the fifth and sixth intercostal motor nerves. Simultaneous triceps motor neurotization, using the third and fourth intercostal nerves, is performed to restore elbow extension. (Copyright of the Mayo Foundation. Reproduced with permission.)

Sensory Evaluation. Patients were followed to assess recovery of sensation. Clinical examination was performed to the presence of a Tinel sign and return of sensibility and temperature discrimination. Sensory recovery was graded based on the modified Highet scale (Table 3 ). ${ }^{8}$

\section{RESULTS}

Of the 29 functioning gracilis muscle transfers reported five failed. Two of the double-stage FFMT grafts failed because of vascular insufficiency. In Case 3, the graft failed because the reflow phenomenon did not occur at the time of the second muscle transfer. In Case 5 a postoperative arterial thrombosis occurred that could not be salvaged during the second transfer procedure. One failure was also noted in the patient in Case 6 in whom the second muscle transfer did not function despite EMG evidence of reinnervation. The two other failures were seen in patients undergoing single gracilis transfers for elbow flexion. In both patients (Cases 6 and 8), the grafted muscle survived but there was no return of function.
Recovery of motor function was graded using a modification of the BRMC grading system (Table 3). The overall functional results were considered excellent (Grade M5), good (Grade M4), fair (Grade M3), and poor (grades $<$ M2). During a minimum follow-up period of 1 year, function was graded as less than or equal to M2 in five cases, M3 in eight, M4 in four, and M5 in 12 (Tables 4 and 5).

Transfer for combined elbow flexion and wrist extension compared with elbow flexion alone lowered the overall results for elbow flexion strength. Seventy-nine percent of the FFMTs for elbow flexion alone (single transfer) and $63 \%$ of similarly innervated muscles transferred for combined motion (Doi Stage I) achieved greater than or equal to M4 elbow flexion strength ( $p>0.05)$.

In comparing the functional results between Doi Stage I and II procedures, six of eight Stage I transfers for elbow flexion/wrist extension yielded greater than or equal to M4 function. In contrast, only one of the Doi Stage II procedures for finger flexion achieved Grade M4 function. Only two of seven patients who underwent a two-stage 


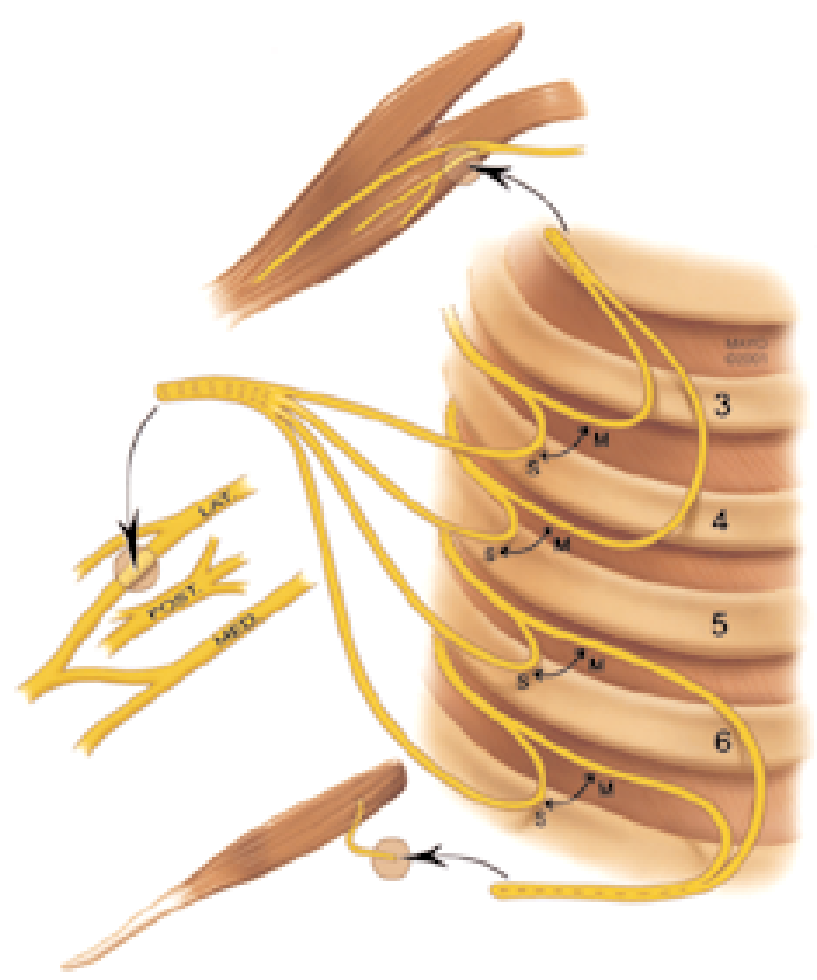

Fig. 3. Motor and sensory neurotization in the second stage of the Doi double free muscle transfer. Gracilis motor neurotization is conducted using the fifth and sixth intercostal motor nerves; triceps neurotization involves the third and fourth intercostal motor nerves; and sensory neurotization requires the lateral cord of the median nerve by using the third to six intercostal sensory nerves three through six. (Copyright of the Mayo Foundation. Reproduced with permission.)

free muscle transfer experienced return of protective sensibility.

\section{DISCUSSION}

Loss of upper-extremity function following a traumatic BPI results in devastating functional deficits that require complex surgical reconstruction. Because of advances and innovations in surgical techniques, elbow flexion and shoulder stability can be reliably restored, when intervention is prompt. Recently, innovations have led to additional surgical reconstructive options that can be expected to improve functional outcomes. For example, methods are available that at times may restore basic grasping function in cases of lower plexus rupture or avulsion. In many such reconstructive schemes, microvascular transfer of muscle to the paralyzed limb is an integral part of the total reconstructive plan. For both the reconstructive team and patient, the complexity and rigor of these procedures are substantial. Successful outcomes require not only consideration of the nature of the plexus injury (including location, mechanism, and duration since injury) and presence of associated injuries, but also surgical expertise, practical operative time constraints, and ability to provide and attend prolonged postoperative rehabilitation.

Differentiation between preganglionic (root avulsion) and postganglionic (nerve rupture) lesions is critical for determining the appropriate type of reconstructive procedure. Treatment of postganglionic lesions should include nerve grafting and nerve transfer (neurotization) techniques involving intra- and extraplexal donor nerves. At times FFMTs are also indicated when all but one nerve root is avulsed or when a treatment delay greater than 6 to 8 months has occurred. Many authors have reported favorable outcomes - restoration of both elbow flexion and shoulder abduction-using these procedures. ${ }^{2,5,6,13,14,17-19,21,22}$

Nerve root avulsions in the spinal cord (preganglionic lesions) are currently irreparable. Only extraplexal neurotization of key muscles or the use of FFMTs is then possible. In patients treated in a timely fashion, direct biceps neurotization by intercostal nerve crossing has reliably restored elbow flexion. This may be combined with neurotization of the shoulder girdle muscles and median nerve by grafting the spinal accessory, phrenic, or contralateral C-7 nerve roots. In addition, Doi, et al., ${ }^{10}$ have introduced the two-stage free muscle transfer procedure as an alternative with the goal of providing more reliable hand function.

One major problem involved in brachial plexus reconstruction is the limited number of donor motor nerves available for neurotization. In the past many different nerves have been grafted including the hypoglossal nerve (12th cranial nerve), spinal accessory nerve (11th cranial nerve) phrenic nerve, intercostal sensory or motor nerves, motor branch of the deep cervical plexus, and contralateral C-7 nerve root. ${ }^{4}$ Although there is no consensus as to which extraplexal motor nerves are the most suitable donors, the intercostal and the spinal accessory nerves have been the most frequently used to restore upper-extremity function. ${ }^{17}$

In the case of complete brachial plexus avulsions (preganglionic lesions), prognosis for restoration of function has been guarded. Functional restoration in patients who present with an insensate, completely flaccid upper-extremity remains challenging. In the past, priority has been given to restoring elbow function and stabilizing the shoulder. Nerve transfer techniques have led to satisfactory results in the restoration of both shoulder abduction and elbow flexion within the 1 st year following injury:2,5,6,13,14,17-19,21,22 however, treatment options are severely limited when patients present after a delay of 9 to 12 months. Long-standing denervation results in irreversible muscle atrophy and fibrosis, and direct neurotization is no longer a viable option. The only option to restore function is through a free muscle transfer with extraplexal neurotization. These grafting procedures are now considered routine for restoring elbow function after prolonged delay postinjury. ${ }^{1,3,7-12}$

Another major benefit to the use of FFMTs is the possibility of providing prehensile function..$^{3,7-12}$ In the past, in the setting of a BPI this was not successful because of the distance between nerve repair site and motor endplates and because of the resulting prolonged reinnervation time. Recently Doi, et al., ${ }^{7-12}$ and others ${ }^{3}$ have demonstrated success at restoring prehension by performing free muscle transfers alone or with the simultaneous reconstruction of two functions by one free muscle transfer. 


\section{Gracilis muscle transfer after BPI}

TABLE 4

Functional results after single gracilis muscle transfer

\begin{tabular}{|c|c|c|c|c|c|c|}
\hline $\begin{array}{l}\text { Case } \\
\text { No. }\end{array}$ & $\begin{array}{l}\text { Follow-Up } \\
\text { Period (mos) }\end{array}$ & $\begin{array}{l}\text { Mos to EMG } \\
\text { Reinnervation }\end{array}$ & $\begin{array}{c}\text { Elbow ROM } \\
\text { Extension- } \\
\text { Flexion }\left(^{\circ}\right)\end{array}$ & $\begin{array}{c}\text { TAM } \\
\left({ }^{\circ}\right)\end{array}$ & $\begin{array}{l}\text { BMRC } \\
\text { Grade }\end{array}$ & Secondary Procedures \\
\hline 1 & 35 & 4 & $-20 / 120$ & NA & M5 & $\begin{array}{l}\text { palmaris longus to extensor pollicis longus; flexor digitorum } \\
\text { superficialis (III) to extensor digitorum comminus }\end{array}$ \\
\hline 2 & 12 & 3 & $-40 / 130$ & NA & M5 & wrist disarticulation \\
\hline 3 & 18 & 6 & $0 / 100$ & NA & M4 & NA \\
\hline 4 & 16 & 6 & $-40 / 85$ & NA & M3 & NA \\
\hline 5 & 47 & 4.5 & $-30 / 130$ & NA & M5 & NA \\
\hline 6 & 22 & 12 & $0 / 0$ & NA & M0 & reexploration of nerve anastomosis \\
\hline 7 & 12 & 4 & $-15 / 105$ & NA & M5 & $\begin{array}{l}\text { rt wrist arthrodesis palmaris longus to extensor pollicis longus } \\
\& \text { extensor digitorum comminus }\end{array}$ \\
\hline 8 & 12 & - & $0 / 0$ & NA & M0 & revision neurotization ICNs $3 \& 4$ \\
\hline 9 & 96 & 3 & $-20 / 120$ & NA & M5 & rt shoulder arthrodesis rt wrist dorsal tenodesis \\
\hline 10 & 42 & 3 & $-35 / 130$ & NA & M5 & NA \\
\hline 11 & 110 & 3 & $-10 / 95$ & NA & M5 & NA \\
\hline 12 & 16 & - & $-15 / 140$ & NA & M5 & NA \\
\hline 13 & 112 & 6 & $-25 / 140$ & NA & M5 & $\begin{array}{l}\text { pronator teres to extensor carpi radialis longus; flexor digitorum } \\
\text { superficialis (III) to extensor carpi radialis brevis; flexor } \\
\text { digitorum superficialis (IV) to extensor digitorum comminus } \\
\text { \& extensor pollicis longus }\end{array}$ \\
\hline 14 & 19 & 6 & $-10 / 100$ & NA & M5 & $\begin{array}{l}\text { brachioradialis to extensor carpi radialis brevis; flexor carpi } \\
\text { ulnaris to A2 pulleys (II-V) }\end{array}$ \\
\hline $15 \dagger$ & 17 & 6 & NA & 30 & M3 & NA \\
\hline
\end{tabular}

* II = index finger; III = middle finger; IV = ring finger; V = small finger; NA = not applicable; $-=$ no reinnervation.

$\dagger$ Transfer for finger flexion.

The two-stage free muscle transfer takes advantage of the length of the gracilis muscle and proximal location of its neurovascular pedicle to promote rapid muscle reinnervation while allowing for distal joint function. A direct neurotization of the spinal accessory nerve to a gracilis muscle fixed to the clavicle can produce elbow flexion and finger or wrist extension (Fig. 2 left), whereas the second transfer, secured to the second rib and neurotized to intercostal motor nerves, creates finger flexion (Fig. 2 right). Creative use of additional intercostal nerves for triceps function and sensory neurotization of the hand allows independent elbow flexion-extension and hand grasp-release functions if all components of the procedure are successful (Fig. 3). Using a double free muscle trans- fer, Doi, et al., ${ }^{8}$ were able to restore excellent-to-good elbow flexion in $96 \%$ of their patients. In addition, greater than $30^{\circ}$ of total active finger motion was restored in $65 \%$ with the second muscle transfer. This study demonstrated that double free muscle transfers can provide useful prehensile function in addition to elbow flexion.

In the setting of complete brachial plexus avulsion, results of current methods frequently provide some hand function in addition to useful shoulder and elbow movement. Because the restored function is somewhat crude or imprecise, definition of a successful outcome is not always clear. It is important that patient's expectations regarding functional outcome be realistic and that they be committed to the lengthy, critical postoperative rehabilita-

TABLE 5

Functional results after double gracilis muscle transfers

\begin{tabular}{|c|c|c|c|c|c|c|c|c|}
\hline \multirow[b]{2}{*}{$\begin{array}{l}\text { Case } \\
\text { No. }\end{array}$} & \multirow[b]{2}{*}{$\begin{array}{l}\text { Follow-Up Mos } \\
\text { (1st T/2nd transfer) }\end{array}$} & \multirow[b]{2}{*}{$\begin{array}{c}\text { Mos to EMG } \\
\text { Reinnervation } \\
\text { (1st T/2nd transfer) }\end{array}$} & \multicolumn{2}{|c|}{ Elbow Function } & \multicolumn{2}{|c|}{ Finger Function } & \multirow[b]{2}{*}{$\begin{array}{l}\text { Return of } \\
\text { Sensibility }\end{array}$} & \multirow[b]{2}{*}{ Secondary Procedures } \\
\hline & & & Extension/Flexion & $\begin{array}{l}\text { BMRC } \\
\text { Grade }\end{array}$ & $\begin{array}{c}\text { TAM } \\
\left({ }^{\circ}\right)\end{array}$ & $\begin{array}{l}\text { BMRC } \\
\text { Grade }\end{array}$ & & \\
\hline 1 & $41 / 43$ & $-1-$ & $-45 / 95$ & M3 & 30 & M3 & no & - \\
\hline 2 & $41 / 43$ & $4.5 / 7$ & $-45 / 130$ & M5 & 60 & M4 & yes & $\begin{array}{l}\text { tenolysis of both gracilis } \\
\text { transfers; creation of } \\
\text { pulley at elbow }\end{array}$ \\
\hline 3 & $44 /-$ & $6 /-$ & $-30 / 120$ & M5 & - & - & no & $\begin{array}{l}\text { abandoned Doi Stage II } \\
\text { secondary to no } \\
\text { reflow phenomenon }\end{array}$ \\
\hline 4 & $30 / 33$ & $6 / 6$ & $-25 / 90$ & M4 & 30 & M3 & no & - \\
\hline 5 & $12 / 11$ & $-1-$ & $-60 / 120$ & M3 & - & - & no & $\begin{array}{l}\text { 2nd gracilis muscle } \\
\text { transfer failed due to } \\
\text { arterial thrombus }\end{array}$ \\
\hline 6 & $15 / 18$ & $3 / 3$ & $-45 / 120$ & M4 & 0 & M0 & no & - \\
\hline 7 & $48 / 46$ & $6 / 3$ & $-60 / 120$ & M3 & 10 & M2 & no & - \\
\hline 8 & $12 / 9$ & $-1-$ & $-40 / 125$ & M4 & 30 & M3 & yes & tenolysis \\
\hline
\end{tabular}


tion prior to undergoing reconstruction. Some patients may choose to focus on a single procedure that yields elbow flexion, as opposed to a complicated, staged procedure such as the double free muscle transfer, once they understand the expected outcomes. In the present study, FFMTs were used to restore motor function either because the duration between injury and surgery was greater than 1 year or because the patient wished for restoration of prehensile function. If restoration of prehension was the goal, a double free muscle transfer was performed.

At our institution we have slightly modified the double free muscle transfer originally described by Doi and colleagues. ${ }^{7-12}$ In the Stage I procedure, the gracilis muscle is secured to wrist extensors as opposed to finger extensors. We believe this helps promote finger flexion through a tenodesis effect. In addition, we have recently altered the route of the first gracilis muscle transfer to create a more effective pulley at the elbow by using the flexor carpi ulnaris muscle. When the brachioradialis muscle was used to create a pulley, as originally described by Doi, et al., we encountered bowstringing of the first gracilis muscle transfer at the elbow. To create a more effective pulley we detached the distal portion of the flexor carpi ulnaris and created a pulley at the level of the proximal forearm (Fig. 4). We believe this will improve muscle excursion and strengthen wrist extension.

In performing the two-stage free muscle transfers we were unable to restore prehension consistently. Two factors may have contributed to our inability to obtain useful prehension: the need for tenolysis and poor compliance with postoperative therapy and follow-up examination.

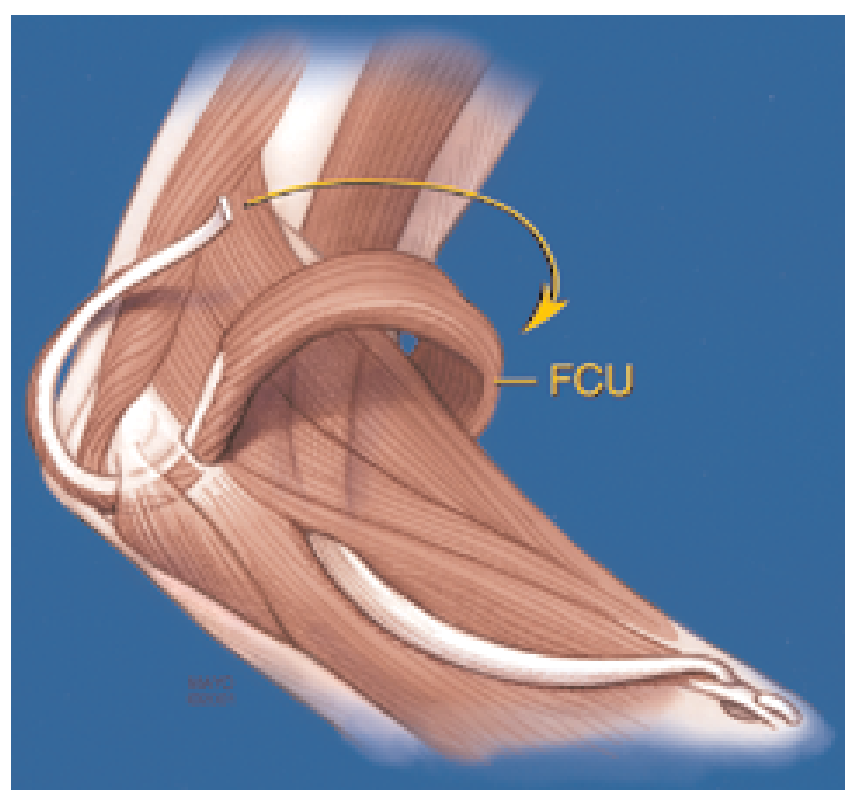

Fig. 4. Creation of a pulley at the proximal forearm is performed using the flexor carpi ulnaris muscle. The tendinous portion of the muscle is detached distally and woven through the anconeous and extensor tendons on the lateral aspect of the elbow. The remaining tendon is passed over the gracilis and secured to the medial epicondyle. (Copyright of the Mayo Foundation. Reproduced with permission.)
Scarring of the wrist and finger tendons is a major postoperative problem after FFMTs. It may be that modification of surgical techniques, such as the use of silicone wraps, may be necessary to promote tendon gliding. Doi, et al., ${ }^{8}$ noted improved active finger flexion after performing a tenolysis in patients in whom there was poor active finger flexion despite strong contraction of the transferred muscle. In their study, nine of 26 patients who underwent a gracilis transfer for combined restoration of elbow ROM and prehension experienced significantly improved finger ROM following tenolysis of the muscle transfer. Only two patients in our study underwent a secondary tenolysis procedure largely because many of these patients were unavailable for follow-up evaluation. Although all patients were encouraged to participate in postoperative rehabilitation, the majority attended less than 1 year of rehabilitation. Noncompliance with postoperative rehabilitation may explain why we were unable to duplicate the results seen in many of the Asian studies.

In the present series, $79 \%$ of the gracilis FFMTs for elbow flexion alone (single transfer) achieved greater than or equal to M4 elbow flexion strength. This is in contrast to $63 \%$ of similarly innervated muscles transferred for combined motion (Doi Stage I procedure) in whom greater than or equal to M4 elbow flexion strength was achieved. Although good-to-excellent muscle function outcomes are possible when undertaking the simultaneous two-function reconstruction via a single FFMT, more reliable results are obtained with the transfer of a single muscle for a single function.

In the treatment of complex BPIs a combination of surgical procedures is necessary to restore motor function. Our results provide additional support for using FFMTs as a reconstructive option for patients who have sustained complete brachial plexus avulsions or when there has been a time delay of more than 1 year between injury and surgery. The decision to undertake a single- or a two-stage free muscle transfer should be based on timing of the surgery, the patient's expectations of outcome, and the availability of other reconstructive options.

\section{Acknowledgments}

We thank Sheri Merten, R.N., for her help in collecting the data used in this manuscript.

\section{References}

1. Akasaka Y, Hara T, Takahashi M: Free muscle transplantation combined with intercostal nerve crossing for reconstruction of elbow flexion and wrist extension in brachial plexus injuries. Microsurgery 12:346-351, 1991

2. Allieu Y, Cenac P: Neurotization via the spinal accessory nerve in complete paralysis due to multiple avulsion injuries of the brachial plexus. Clin Orthop 237:67-74, 1988

3. Berger A, Flory PJ, Schaller E: Muscle transfers in brachial plexus lesions. J Reconstr Microsurg 6:113-116, 1990

4. Chuang DC: Neurotization procedures for brachial plexus injuries. Hand Clin 11:633-645, 1995

5. Chuang DC, Lee GW, Hashen F, et al: Restoration of shoulder abduction by nerve transfer in avulsion brachial plexus injury: evaluation of 99 patients with various nerve transfers. Plast Reconstr Surg 96:122-128, 1995

6. Chuang DC, Yeh MC, Wei FC: Intercostal nerve transfer of the 


\section{Gracilis muscle transfer after BPI}

musculocutaneous nerve in avulsed brachial plexus injuries: evaluation of 66 patients. J Hand Surg Am 17:822-828, 1992

7. Doi K: New reconstruction procedure for brachial plexus injury. Clin Plast Surg 24:75-85, 1997

8. Doi K, Muramatsu K, Hattori Y, et al: Restoration of prehension with the double free muscle technique following complete avulsion of the brachial plexus. Indications and long-term results. J Bone Joint Surg Am 82:652-666, 2000

9. Doi K, Sakai K, Fuchigami Y, et al: Reconstruction of irreparable brachial plexus injuries with reinnervated free-muscle transfer. Case report. J Neurosurg 85:174-177, 1996

10. Doi K, Sakai K, Kuwata N, et al: Double free-muscle transfer to restore prehension following complete brachial plexus avulsion. J Hand Surg Am 20:408-414, 1995

11. Doi K, Sakai K, Kuwata N, et al: Reconstruction of finger and elbow function after complete avulsion of the brachial plexus. J Hand Surg Am 16:796-803, 1991

12. Doi K, Shigetomi M, Kaneko K, et al: Significance of elbow extension in reconstruction of prehension with reinnervated free-muscle transfer following complete brachial plexus avulsion. Plast Reconstr Surg 100:364-372, 1997

13. Krakauer JD, Wood MB: Intercostal nerve transfer for brachial plexopathy. J Hand Surg Am 19:829-835, 1994

14. Leechavengvongs $\mathrm{S}$, Witoonchart $\mathrm{K}$, Uerpairojkit $\mathrm{C}$, et al: Nerve transfer to biceps muscle using a part of the ulnar nerve in brachial plexus injury (upper arm type): a report of 32 cases. J Hand Surg Am 23:711-716, 1998

15. Manktelow RT: Microvascular Reconstruction: Anatomy, Applications, and Surgical Technique. New York: SpringerVerlag, 1986, pp 151-164
16. Manktelow RT, Zuker RM, McKee NH: Functioning free muscle transplantation. J Hand Surg Am 9:32-39, 1984

17. Merrell GA, Barrie KA, Katz DL, et al: Results of nerve transfer techniques for restoration of shoulder and elbow function in the context of a meta-analysis of the English literature. J Hand Surg Am 26:303-314, 2001

18. Mikami Y, Nagano A, Ochiai N, et al: Results of nerve grafting for injuries of the axillary and suprascapular nerves. J Bone Joint Surg Br 79:527-531, 1997

19. Narakas AO, Hentz VR: Neurotization in brachial plexus injuries. Indication and results. Clin Orthop 237:43-56, 1988

20. Ruch DS, Friedman A, Nunley JA: The restoration of elbow flexion with intercostal nerve transfers. Clin Orthop 314: 95-103, 1995

21. Songcharoen P, Mahaisavariya B, Chotigavanich C: Spinal accessory neurotization for restoration of elbow flexion in avulsion injuries of the brachial plexus. J Hand Surg Am 21: 387-390, 1996

22 Waikakul S, Wongtragul S, Vanadurongwan V: Restoration of elbow flexion in brachial plexus avulsion injury: comparing spinal accessory nerve transfer with intercostal nerve transfer. J Hand Surg Am 24:571-577, 1999

Manuscript received March 23, 2004

Accepted in final form April 2, 2004.

Address reprint requests to: Allen T. Bishop, M.D., Department of Orthopaedic Surgery, Division of Hand Surgery, Mayo Clinic, 200 First Street SW, Rochester, Minnesota 55905. Bishop.allen@ mayo.edu. 